\title{
Fear of pregnancy and childbirth
}

\author{
K Hofberg, M R Ward
}

Postgrad Med J 2003;79:505-510

Pregnancy is a major life event for all women. However, when a psychiatric disorder is added to or exacerbated by the pregnancy then the problem requires expert knowledge from more than one area of medicine. This paper looks at pregnancy and the relationship with depression, eating disorders, and pathological fear of childbirth or tokophobia. It also examines the outcome for these women and their babies. Mental illness is a serious concern. It is now recognised that death from suicide is the leading cause of maternal death overall. Research in these areas is relatively sparse but an attempt is made to collate what is known.

See end of article for authors' affiliations

Correspondence to: Dr Kristina Hofberg, Trust $\mathrm{HQ}$, South Staffordshire Healthcare NHS Trust, St George's Hospital, Stafford ST 16 3AG, UK; Kristina.Hofberg@virgin.net

Submitted 19 September 2002

Accepted 26 March 2003
A lthough the state of pregnancy is both normal for, and often desired by, women in learly adulthood, it is not uncommon to experience anxiety at the physical and emotional consequences of the gravid state. It is not the purpose of this paper to comment on psychiatric and psychological descriptions of the "normal" pregnant woman but concentrate on some pathological psychiatric conditions that may effect pregnant women. Anxiety and fear of pregnancy and childbirth are documented features of eating disorders, mood disorders, and pathological dread and avoidance of childbirth or tokophobia.

There are disorders in which anxiety is the primary symptom of a pathological mental state. First medically described by Marcé in the 18th century, the disorders of anxiety during pregnancy, especially those in the first trimester have profound features of turmoil. ${ }^{1}$ Paradoxically, some women with a pregravid anxiety disorder have a decrease of symptoms in the first trimester. ${ }^{2}$ Some level of anxiety may be protective and a portrait of the primiparous woman most likely to have a positive birth experience was proposed as anxious and realistically fearful, yet competent in her knowledge of labour and delivery. ${ }^{3}$

\section{DEPRESSION RELATED TO PREGNANCY AND CHILDBIRTH}

Although depressive illness is often perceived as a disorder of postnatal mothers it is, in fact, as common in pregnant women. ${ }^{4-7}$ Postnatal depression has become a focus of concern and the consequences to the child, mother, and family may include neglect of the child, family breakdown, self harm, and suicide. Research also suggests that the babies may develop emotional or behavioural problems or cognitive delays in childhood. $^{89}$

In contrast, depression during pregnancy has been relatively neglected. Indeed, pregnancy has been thought to protect against depression. Studies of antenatal psychopathology have mostly examined antenatal mood as a predictor of postnatal depression. ${ }^{10}$

Watson et al found that in $23 \%$ of those with postnatal depression, this had started during pregnancy. ${ }^{11}$ Depressed mood during pregnancy has also been associated with poor attendance at antenatal clinic, substance misuse, low birth weight, and preterm delivery. Psychopathological symptoms during pregnancy have physiological consequences for the fetus and this may explain some of these effects. ${ }^{12}$

There is good research, dating back to that of Esquirol in 1818, describing all pregnancy related mental illness. He called this "puerperal insanity" and included recurrent prenatal depression. ${ }^{13}$ More recent studies, such as those by Menzies ${ }^{14}$ and Knauer, ${ }^{15}$ have reinforced the extent and severity of prenatal depression. Evans et al suggest that the proportion of women rating themselves as severely depressed was similar before and after childbirth. ${ }^{16}$ They suggest that postnatal depression is not a distinct syndrome. Their data suggest that childbirth is less likely than the events of pregnancy to be followed by depression in women who are not depressed. Furthermore, depressed women are more likely to improve after childbirth. These conclusions have been challenged. ${ }^{17}$

Ramrakha et al identified an increased probability of "risky sex" across a range of mental health diagnoses. ${ }^{18}$ Even clinical depression was associated with increased rates of "risky sex", sexually transmitted diseases, and early sexual experience. With regard to sexual initiation, other questions arise, such as the role of sexual abusealso a major precursor to mental health disorder. Risk taking may represent an indirect expression of anger or a mechanism for exerting control over one's life. For a depressed young person, sexual activity and the associated risks may be seen as a diversion, a relief of tension or a salve of affection seeking—a self medication with sex. ${ }^{19}$

Depression is never trivial in mothers. The severity of the illness can have catastrophic consequences. It is a tragedy that some women die in the aftermath of childbirth. In fact, when all deaths in the year after delivery are taken into account, the Confidential Enquiry into Maternal Deaths showed that deaths from suicide are not only the leading cause of indirect death, but also the leading cause of maternal death overall. ${ }^{20}$ For some the fatal outcome may have been avoided.

\section{INFANTICIDE}

Although the deliberate killing of a child by the mother has been described from ancient times, it is probably more reasonable to consider this act in two forms. These are the customary neonaticide 
of unwanted newborn babies and the killing of children for other reasons.

Neonaticide has often been focused on the differential killing of female children. This has led to a substantial shift in the number of reported male births to female births, figures sometimes exceeding 3:1. Although this is less common as contraception becomes more available, there are still areas of the world in which female babies are deliberately killed.

It is not the purpose of this article to look at the psychopathological causes for infanticide, nor the law surrounding it. However, the reader may wish to review the excellent chapter in Motherhood and Mental Health by Emeritus Professor Brockington (see additional reading)

\section{EATING DISORDERS}

\section{Anorexia nervosa}

Eating disorders or disordered eating behaviours frequently occur in the childbearing years. The defining psychopathology of anorexia nervosa is a phobic avoidance of normal body weight. There are comments in the literature, often repeated, that there is an "antagonism" between anorexia nervosa and reproduction, because of the cessation of menstruation in active cases of anorexia nervosa. Pregnancy is rare in active anorexia nervosa except where ovulation has been induced. ${ }^{21}$

There are several studies that look at the outcome of pregnancy after recovery from the disorder. ${ }^{22-24}$ There are also case reports of pregnancy occurring in women who had not yet recovered. At follow up, the babies born to these women have, as a group, abnormally low birth weights. ${ }^{25} \mathrm{~A}$ higher rate of stillbirths is reported. ${ }^{24}$ These women may have more premature births and caesarean sections. Research suggests no difference between those with active and remitted symptoms of anorexia nervosa as a variable. ${ }^{26}$

\section{Bulimia nervosa}

Bulimia nervosa is characterised by a loss of control over eating, with self perpetuating cycles of bingeing and purging. It is common $^{27}$ and highly responsive to specific forms of psychotherapy. ${ }^{28}$ Women who suffer from this condition generally improve during pregnancy. ${ }^{29}$ However, there is some research to suggest that the babies of bulimic mothers are premature and underweight. ${ }^{30}$ Although bulimic symptoms may improve as the pregnancy progresses for the majority of women, over half had worse symptoms after pregnancy than before. Severe bulimic symptoms at conception, a history of anorexia nervosa, gestational diabetes, and unplanned pregnancy all predicted relapse. Postpartum depression occurred in one third of the group and was predicted by the presence of a lower body mass index at conception, a higher frequency of bingeing after delivery, and a higher weekly alcohol intake at conception. Two thirds of those with a history of anorexia nervosa reported postpartum depression. ${ }^{31}$ The findings of the studies published to date, while somewhat inconsistent, suggest that both anorexia nervosa and bulimia nervosa may negatively effect fetal outcome. Together the data suggest that having a past or current eating disorder may put a mother and her infant at risk for problems during pregnancy. ${ }^{32}$

\section{Sexuality and eating disorders}

Seminal descriptions of anorexia nervosa by Lasegue in 1873 cited difficulties in heterosexual relationships as aetiological. ${ }^{33}$ This notion has often been repeated but rarely substantiated. Studies of sexuality and anorexia nervosa do suggest an association with body mass index but have been limited by cross sectional ${ }^{34}$ or retrospective study designs. ${ }^{35}$ The latter study also suggested that sexual activity in anorexia nervosa does not necessarily reflect levels of sexual interest or enjoyment. This disparity between drive and behaviour resonates with the similar disparity between hunger and feeding behaviour in anorexia nervosa, demonstrating the core subversion of appetitive behaviour. Balakrishna and Crisp have suggested that anorexia nervosa represents an avoidance response to the sexual thrust of puberty, ${ }^{36}$ while Tuiten et al have argued that changes in sexuality are solely due to the hypogonadism of emaciation. ${ }^{37}$ There are apparent differences in psychosexual histories between patients with restrictive anorexia nervosa, purging anorexia nervosa, and bulimia nervosa. Purging anorectics report more past sexual history than restrictive anorectics, ${ }^{35}$ while women with bulimia are generally more sexually active and experienced than even women without an eating disorder, with greater lifetime numbers of sexual partners and higher rates of induced abortion. ${ }^{38}$ Oral contraceptives are inappropriate and unreliable in the presence of regular self induced vomiting. ${ }^{21}$ High levels of childhood sexual abuse are reported to be associated with eating disorders. ${ }^{21}$

\section{MISCARRIAGE}

It has historically been very difficult to accurately estimate the rate of miscarriage in comparison to completed pregnancies. Research has discussed the estimated rates between 1845 and 1933 before readily available termination. ${ }^{39}$ More recently, diagnosing pregnancy using radioimmunoassay showed that $43 \%$ of all pregnancies were lost by spontaneous abortion, ${ }^{40}$ a large percentage of these not recognised by the woman.

There are well documented psychological and psychiatric consequences to a miscarriage. ${ }^{41}$ Seven percent of all miscarriages occur in women who have recurrent spontaneous abortion, ${ }^{39}$ although more recently the likelihood of successful subsequent pregnancy is much better. ${ }^{42}$

\section{TERMINATION OF PREGNANCY}

The psychological and psychiatric effects of termination are complex and often related to the reason for that termination. In the large study of Ekblad the author came to a conclusion that was subsequently often repeated, that is, "The greater the psychiatric indication the greater the risk of adverse sequelae" ${ }^{43}$ In addition, it should be noted that all the postpartum psychiatric complications may also occur after termination of pregnancy. Some women have intense and vivid fantasies of "killing the baby" for over a year. ${ }^{44}$ It has been suggested that "almost every woman who entertained the thought of obtaining a termination, however briefly, became depressed in pregnancy or after delivery". ${ }^{45}$ In one study two women terminated a pregnancy because they were too terrified to endure a delivery. ${ }^{46}$ Termination may be requested by women who suffer from tokophobia, dearly want a baby, but are unable to understand their own aversion to parturition. In the absence of an empathic professional ear or relevant medical literature their only choice may be to terminate the pregnancy and live with the psychological impact of that decision.

Psychological maladjustments after abortion are significantly associated with a history of depression. It has been suggested that prior psychological state is equally predictive of subsequent depression among women with unintended pregnancies regardless of whether they abort or carry to term. ${ }^{47}$ Reardon and Cougle challenge this. ${ }^{48}$ They suggest that married women who carry an unplanned pregnancy to term were at less risk of depression than married women who aborted. Single women, however, had high depression scores independent of outcome.

\section{PATHOLOGICAL DREAD AND AVOIDANCE OF CHILDBIRTH (TOKOPHOBIA) Prevalence of fear of pregnancy and childbirth}

Fear of childbirth is common and more intense in pregnant nulliparous women than in pregnant parous women. ${ }^{49}{ }^{80}$ Over $20 \%$ of pregnant women report fear and $6 \%$ describe a fear 
that is disabling. ${ }^{5152}$ Altogether $13 \%$ of non-gravid women report fear of childbirth sufficient to postpone or avoid pregnancy. ${ }^{53}$

It is well known that pregnancy may be a time of considerable anxiety with symptoms escalating in the third trimester. ${ }^{54}$ Women still suffer from the fear of death during delivery. ${ }^{55}$ When this specific anxiety or fear of death during parturition precedes pregnancy and is so intense that tokos (childbirth) is avoided whenever possible, this is a phobic state called "tokophobia". Tokophobia may effect women from childhood into old age.

\section{Prevalence of anxiety}

In 1941 Sontag warned that a woman's emotional state could effect her pregnancy. ${ }^{56}$ He stated "deeply disturbed maternal emotion produces a marked increase in activity of the fetus". Many researchers have subsequently studied the causes and consequences of maternal anxiety and fear. Fear of pain is often reported as the reason for fearing delivery. Fearful women with free access to analgesic drugs during labour were still more likely to experience childbirth negatively and suffer severe emotional imbalance postpartum. Thus "fear of pain" in a Western society may be a culturally accepted way of expressing something more complex. ${ }^{57}$ More recently, pregnant women fearful of childbirth reported a lack of trust in the obstetric team, fear of their own incompetence and fear of dying. ${ }^{58}$ Other studies have suggested that the greatest fear was of delivering a physically damaged or congenitally malformed child. ${ }^{59}$ Women who have suffered childhood sexual abuse or rape fear the experience of childbirth will revisit the distress and helplessness of abuse. Women who have already suffered during childbirth are afraid of retraumatisation..$^{53}$

\section{Treatment studies for fear of childbirth}

Women with dread of childbirth are vulnerable to increased surgical intervention and subsequent psychological complications. Studies investigating the alleviation of fear of childbirth date back to the 1920s. ${ }^{61}$ Psychoprophylaxis was investigated in the $1950 \mathrm{~s}^{62}$ and more recently the benefits of hypnosis. ${ }^{63}$

A psychoprophylactic preparation course offered to pregnant women afraid of childbirth made no significant difference to obstetric outcome. ${ }^{64}$ Psychological outcomes were not investigated. Important research has been conducted in Sweden. Ryding, an obstetrician and psychotherapist, offered either counselling or short term psychotherapy to pregnant women demanding a caesarean section that the obstetrician thought unnecessary. ${ }^{65}$ At term, half these women chose vaginal delivery. Sjogren investigated 72 women with severe anxiety about childbirth. ${ }^{66}$ They were offered psychotherapy or extra obstetric support. Subsequently, some women chose a vaginal delivery. These women experienced the delivery as positively as a reference group. Tokophobic women who strongly desired a surgical delivery and were refused suffered greater psychological morbidity than those granted their chosen delivery method. ${ }^{53}$ The number of women demanding elective caesarean section because of tokophobia is not known. The National Sentinel Caesarean Section Audit was published in October 2001. The audit found that one in five $(21.5 \%)$ of births in England and Wales were by caesarean section; $7 \%$ of these were at the mother's request with no medical reason. ${ }^{67}$

\section{TOKOPHOBIA CLASSIFICATION}

Tokophobia has been classified as follows:

- Primary-nulliparous.

- Secondary-previous traumatic deliveries.

- Secondary to depressive illness in pregnancy.

\section{(1) Secondary tokophobia}

Some women develop a dread and avoidance of childbirth after a traumatic obstetric event in a previous pregnancy. Most typically this is a "traumatic" delivery but it could also occur after an obstetrically normal delivery, a miscarriage, a stillbirth, or a termination of pregnancy. Some women feel so traumatised they avoid a further pregnancy even when a baby is desperately wanted.

\section{Secondary tokophobia and the relation to post-traumatic} stress disorder (PTSD)

PTSD is increasingly recognised as a consequence of childbirth and is associated with a pathological dread and avoidance of further pregnancy and childbirth experiences. ${ }^{68}$ In 1875 Savage alluded to "a startling and horrible dream" after childbirth, succeeded by a "melancholy stupor". ${ }^{69}$ Knauer described depression after a severe labour with a resulting phobia for pregnancy in $1897 .{ }^{15}$ However, it was the seminal work by Bydlowski and Raoul-Duval in $1978{ }^{68}$ that documented the "nightmare" of childbirth. ${ }^{68}$ They described 10 cases of "névrose traumatique post-obstétricale" in women who endured long, painful deliveries. They stated:

"Parturition-especially the first—can, by its obligatory violence and confrontation with an imminent and lonely death put the mother under extreme stress".

They suggested that the aftermath of delivery trauma was intensified in a subsequent pregnancy. These traumatised women avoided childbirth. Some suffered nightmares so terrifying that they were unable to sleep. ${ }^{70}$ The clinical picture and course of PTSD after childbirth was described in four cases in 1995. ${ }^{71}$ PTSD may follow deliveries that "need not have been abnormal from the clinicians perspective" ${ }^{72}$ In extreme and tragic cases, women will terminate much wanted pregnancies because they are unable to deal with the idea of another delivery. ${ }^{53}$ Almost $2 \%$ of women have a "posttraumatic stress symptom profile" related to childbirth in the first year postpartum. ${ }^{73}$ Furthermore, one third of women suffer "serious post-traumatic intrusive stress reactions" in the two months after an emergency caesarean section. ${ }^{74}$ Consequently, post-delivery stress clinics have been developed. ${ }^{75}$

Secondary tokophobia and the "vicious cycle principle" Childbirth impacts on a subsequent delivery. An emergency caesarean section or instrumental vaginal delivery increases fear of childbirth in a subsequent pregnancy. ${ }^{76}$ Additionally, women who suffer from fear of childbirth during pregnancy subsequently have an increased rate of emergency caesarean section or instrumental vaginal delivery ${ }^{64} 7677$

Not surprisingly, the mode of delivery influences women's psychological state after the delivery. Ryding et al reported that women who had an emergency caesarean section or instrumental vaginal delivery suffered more negative psychological reactions after delivery than women experiencing elective caesarean section or normal vaginal delivery. ${ }^{78}$ There is a clear relationship between women's expectations before delivery and experiences after. So, the expectation of being in control (both self control and control over what was done to one) is positively associated with achieving that aim and with higher satisfaction with that delivery. ${ }^{10} 79$

Therefore, the expectation a pregnant woman has about the anticipated delivery might be highly relevant for her experience of and behaviour during the delivery. That is, her appraisal before delivery might influence her appraisal after- "a vicious cycle principle" ${ }^{80}$ For some women the fear lasts many years. ${ }^{49}$

\section{(2) Primary tokophobia}

When dread of childbirth predates the first conception, this is primary tokophobia. The dread of childbirth may start in adolescence or early adulthood. Although sexual relations may be 
normal, contraceptive use is often scrupulous. ${ }^{53}$ Pregnancy is avoided to prevent parturition. In some tragic cases, a woman is so terrified of childbirth, she will terminate a wanted pregnancy rather than go through childbirth. Some women will actively seek out an obstetrician who will perform an elective caesarean section before becoming pregnant for the first time. Some women never overcome their fear of childbirth and remain childless and some adopt. Many feel shame at their perceived inadequacy. Some women enter the menopause having never delivered a much desired baby and grieve this loss into old age.

\section{Aetiology of primary tokophobia}

The aetiology of primary tokophobia is likely to be multifaceted. Psychological and social considerations have been postulated. ${ }^{81}$

\section{A. Social culture}

Fear of childbirth may transmit over generations ${ }^{82}$ and this can produce a second generation effect of a mother's own unresolved frightening experience. ${ }^{83}$ It is suggested that women's reproductive adaptation is like their mother's. This suggests a psychological heredity. ${ }^{83}$ This may be further highlighted for girls when their parents have a negative attitude towards sexuality. ${ }^{76}$ Women accurately recall details of childbirth 20 years later. ${ }^{84}$

\section{B. Anxiety theories}

A phobia is an avoidance response. It may be learnt through frightening experiences, vicariously by seeing other's fearful responses, or through instruction. ${ }^{85} \mathrm{Zar}^{86}$ used the work of Lazarus $^{87}$ to investigate fear of childbirth. She suggested a pregnant woman's expectations of the delivery are relevant to her experiences of and behaviour during delivery. Furthermore, the appraisal of the last delivery will include the anxiety associated with it and indicate the level of fear for a future delivery.

Fear of childbirth has been associated with anxiety proneness in general ${ }^{80}$ and may belong to the family of anxiety disorders.

\section{Trauma and abuse}

Baker and Duncan reported that $12 \%$ of women described being sexually abused before the age of $16{ }^{88}$ Psychological morbidity secondary to childhood sexual abuse may be immense and diverse with increased rates of sexual dysfunction, ${ }^{89}$ anorexia, ${ }^{90}$ and PTSD. ${ }^{91}$

A history of childhood sexual abuse could be associated with an aversion to gynaecological examinations including routine smears or obstetric care. The trauma of vaginal delivery, or even the contemplation of it, may cause a resurgence of distressing memories. This can lead to dread and avoidance of childbirth even when a woman wants a baby. ${ }^{53}$

\section{(3) Tokophobia as a symptom of depression}

Less commonly, prenatal depression may present with tokophobia. With this, there is no morbid dread of childbirth and this fear is in stark contrast to the woman's prepregnancy and predepression beliefs. ${ }^{46}$

\section{CONCLUSION}

Psychological morbidity is common in women during their childbearing years. However, conditions such as PTSD and tokophobia may not have any obvious preceding cause and may be unrecognised. The outcome of all of the conditions considered in this paper is less good than the outcome for other mothers. There is a need for psychiatrists and obstetricians to work together to improve this underrecognised and under-treated group of women and babies.

\section{Further reading}

- Evans J, Francomb H, Oke S, et al. Cohort study of depressed mood during pregnancy and after childbirth. BM 2001;323:257-60.

- Hofberg KM, Brockington IF. Tokophobia: an unreasoning dread of childbirth. Br J Psychiatry 2000;176:83-5.

- Ryding EL, Wijma K, Wijma B. Psychological impact of emergency caesarean section in comparison with elective caesarean section, instrumental and normal vaginal delivery. J Psychosom Obstet Gynaecol 1998;19:135-44.

- Confidential Enquiries into Maternal Deaths in the United Kingdom. Why mothers die. Fifth report 1997-1999. London: RCOG Press, 2001.

- Wijma K, Soderquist J, Wijma B. Post traumatic stress disorder after childbirth: a cross sectional study. Journal of Anxiety Disorders 1997;11:587-97.

- In addition we would like to recommend the reading of Motherhood and Mental Health. This is a comprehensive overview of this specialised area of psychiatry by Emeritus Professor lan Brockington published by Oxford Medical Publications in 1996.

\section{Learning points}

- Deaths from suicide in the year after delivery is the leading cause of maternal death overall.

- When dread and avoidance of childbirth predates the first conception, this is primary tokophobia.

- Secondary tokophobia may be associated with posttraumatic stress disorder, postnatal depression, bonding disorder with the baby, and avoidance of a subsequent pregnancy.

- Women with anorexia nervosa have higher rates of premature births and caesarean section.

- Women with bulimia nervosa often have symptom improvement during pregnancy. However, they often relapse in the postnatal period with more severe symptoms than before conception.

\section{QUESTIONS (T (TRUE)/F (FALSE); ANSWERS AT END OF REFERENCES) \\ 1. Tokophobia:}

(A) Can be found in men

(B) Can start in childhood

(C) Can continue after the menopause

(D) Is a cause of childlessness

\section{Depression:}

(A) Is as common in pregnancy as the postnatal period

(B) May cause tokophobia

(C) If severe and postnatal will delay developmental milestones

(D) Is the second most common cause of death of new mothers

\section{Anorexia nervosa:}

(A) Can cause infertility

(B) If treated successfully improves the obstetric outcome

(C) Is associated with increased caesarean section rate

(D) Is associated with tokophobia

\section{Bulimia nervosa:}

(A) Is associated with reduced libido

(B) Improves during pregnancy

(C) Improves postnatally

(D) Protects against postnatal depression 


\section{Post-traumatic stress disorder after childbirth:}

(A) May cause primary tokophobia

(B) Was described in 1995 by Ballard et al

(C) Responds successfully to debriefing

(D) Is associated with postnatal depression

\section{Tokophobia may be associated with:}

(A) An obstetrically normal delivery

(B) Relationship breakdown during pregnancy

(C) Request for general anaesthetic during delivery

(D) Request for termination

\section{Authors' affiliations}

K Hofberg, M R Ward, South Staffordshire Healthcare NHS Trust, St George's Hospital, Stafford

\section{REFERENCES}

Marcé LV. Traité de la folie des femmes enceintes, des nouvelles accouchées et des nourrices. Paris: Baillière, 1858.

2 George DT, Jay A, Ladenheim JA, et al. Effect of pregnancy on panic attacks. Am J Psychiatry 1987:144:1078-9.

3 Crowe K, von Baeyer C. Predictors of a positive childbirth experience. BIRTH 1989;16:59-63.

4 Nilsson $\AA$, Almgren PE. Para natal emotional adjustment: a prospective investigation of 165 women. Part 1. A general account of background variables, attitudes towards childbirth, and an appreciation of psychiatric morbidity. Part 2. The influence of background factors, psychiatric history, parental relations and personality characteristics. Acta Psychiatr Scand 1970(suppl 220)

5 Uddenberg N. Reproductive adaptation in mother and daughter. Acto Psychiatr Scand 1974(suppl 254).

6 Wolkind S, Zajicek E, ed. Pregnancy: a psychological and social study. London: Academic Press, 1981.

7 Lumley J, Austin M-P. What interventions may reduce postpartum depression. Curr Opin Obstet Gynecol 2001;13:605-11

8 Sinclair D, Murray L. Effects of postnatal depression on children's adjustment to school. Br J Psychiatry 1998;172:58-63.

9 Murray L, Sinclair D, Cooper P, et al. The socioemotional development of 5 year olds with postnatally depressed mothers. J Child Psychol Psychiatry 1999:40:1259-71.

10 Green MJ. Who is unhappy after childbirth? Antenatal and intrapartum correlates from a prospective study. Journal of Reproductive and Infant Psychology 1990;8:175-83.

11 Watson JP, Elliott SA, Rugg AJ, et al. Psychiatric disorder in pregnancy and the first postnatal year 1984. Br J Psychiatry 1984;144:453-62.

12 Teixeira JMA, Fisk NM, Glover V. Association between maternal anxiety in pregnancy and increased uterine artery resistance index: cohort based study. BMU 1999:318:153-7.

13 Esquirol JED. Observations sur l'aliénation mentale à la suite de couches. Journal Général de Médicine, de Chirurgie et de Pharmacie Françaises et Étrangères 1818:2(1):148-64.

14 Menzies WF. Puerperal insanity. An analysis of 140 consecutive cases American Journal of Insanity 1893;50:148-85.

15 Knaver O. Über Puerperale Psychosen, für practische Aerzte. Berlin: Karger, 1897

16 Evans J, Francomb H, Oke S, et al. Cohort study of depressed mood during pregnancy and after childbirth. BM 2001;323:257-60.

17 Oates MR, Lee A. Data do not support idea that depression is more common antenatally then postnatally. BM 2001;323:1367.

18 Ramrakha S, Caspi A, Dickson N, et al. Psychiatric disorders and risky sex: a cross sectional study in a birth cohort. BM 2000;321:263-6.

19 Bennett DL, Bauman A. Adolescent mental health and risky sexual behaviour. BM 2000;321:251-2.

20 Confidential Enquiries into Maternal Deaths in the United Kingdom. Why mothers die. Fifth report 1997-1999. London: RCOG Press, 2001.

21 Morgan JF. Eating disorders and reproduction. Aust N Z J Obstet Gynaecol 1999;39:167-73.

22 Farquharson RF, Hyland $\mathrm{HH}$. Anorexia nervosa: the course of 15 patients treated from 20-30 years previously. CMA 1966;94:411-19.

23 Kohmura H, Miyake A, Aono T, et al. Recovery of reproductive function in patients with anorexia nervosa: a 10-year follow-up study. Eur $J$ Obstet Gynecol Reprod Biol 1986:22:293-6.

24 Brinch $M$, Isager T, Tolstrup K. Anorexia nervosa and motherhood: reproductive pattern and mothering behaviour of 50 women 1988. Acta Psychiatr Scand 1988;77:611-17.

25 Schneider L, Heard I, Bréart G, et al. Maigreur maternelle et grossesse. Archives Francaises de Pédiatrie 1979;36:1068-74.

26 Bulik CM, Sullivan PF, Fear JL, et al. Fertility and reproduction in women with anorexia nervosa: a controlled study. J Clin Psychiatry with anorexia nervo:

27 Kendler KS, MacLean C, Neale M, et al. The genetic epidemiology of bulimia nervosa. Am J Psychiatry 1991;148:1627-37.
28 Fairburn CG, Norman PA, Welch SL, et al. A prospective study of outcome in bulimia nervosa and the long term effects of three psychological treatments. Arch Gen Psychiatry 1995;52:304-12.

29 Lacey JH, Smith G. Bulimia nervosa: the impact of pregnancy on mother and baby. BrJ Psychiatry 1987;150:777-81

30 Stewart DE, Raskin J, Garfinkel PE, et al. Anorexia nervosa, bulimia and pregnancy. Am J Obstet Gynecol 1987; 157:1 194-8.

31 Morgan JF, Lacey JH, Sedgwick PM. Impact of pregnancy on bulimia nervosa. Br J Psychiatry 1999;174:135-40.

32 Franko DL, Blais MA, Becker AE, et al. Pregnancy complications and neonatal outcomes in women with eating disorders. Am J Psychiatry $2001 ; 158: 1461-6$

33 Lasegue EC. On hysterical anorexia. Medical Times and Gazette 1873;2:265-6.

34 Morgan CD, Wiederman MW, Pryor TL. Sexual functioning and attitudes of eating disordered women: a follow-up study. Journal of Sex and Marital Therapy 1995:21:67-77.

35 Beumont PJV, Abraham SF, Simson KG. The psychosexual histories of adolescent girls and young women with anorexia nervosa. Psychol Med $1981 ; 11: 131-40$

36 Balakrishna J, Crisp AH. A pilot programme of sex education for in-patients with anorexia nervosa. Eur Eat Disorders Rev 1998;6:136-42.

37 Tuiten A, Panhuysen G, Everaerd W, et al. The paradoxical nature of sexuality in anorexia nervosa. Journal of Sex and Marital Therapy 1993:19:259-75

38 Abraham SF, Bendit N, Mason C, et al. The psychosexual histories of young women with bulimia. Aust N Z J Psychiatry 1985;19:72-6.

39 Wetterdal P. The frequency of spontaneous abortion 1945. Acta Obstet Gynecol Scand 1945;25:399-411.

40 Miller JF, Willimason E, Glue J, et al. Fetal loss after implantation: a prospective study. Lancet 1980;ii:554-6.

41 Greer HS, Lal S, Lewis SC, et al. Psychosocial consequences of therapeutic abortion. Br J Psychiatry 1976;1 28:74-9.

42 Hall RCW, Beresford TP, Quinones JE. Grief following spontaneous abortion. Psychiatr Clin North Am 1987; 10:405-20.

43 Ekblad M. Induced abortion on psychiatric grounds. Acta Psychiatr Scand 1955(suppl 99).

44 Wallerstein JS, Kurtz P, Bar-Din M. Psychosocial sequelae of therapeutic abortion in young unmarried women. Arch Gen Psychiatry 1972;27:828-32.

45 Kumar R, Robson KM. A prospective study of emotional disorders in childbearing women. BrJ Psychiatry 1984; 144:35-47.

46 Hofberg KM, Brockington IF. Tokophobia: an unreasoning dread of childbirth. Br J Psychiatry 2000;1 76:83-5.

47 Major B, Cozzarelli C, Cooper ML, et al. Psychological responses of women after first-trimester abortions. Arch Gen Psychiatry 2000:57:777-84.

48 Reardon D, Cougle JR. Depression and unintended pregnancy in the National Longitudinal Survery of Youth; a cohort study. BM 2002;324:151-2

49 Melender H-L, Lauri S. Fears associated with pregnancy and childbirth-experiences of women who have recently given birth. Midwifery 1999;15:177-82.

50 Alehagen S, Wijma K, Wijma B. Fear during labor. Acta Obstet Gynecol Scand 2001;80:315-20.

51 Areskog B, Uddenberg N, Kjessler B. Fear of childbirth in late pregnancy. Gynecol Obstet Invest 1981;12:262-6.

52 Searle J. Fearing the worst-why do pregnant women feel "at risk"? Aust N Z J Obstet Gynaecol 1996:36:279-86.

53 Hofberg KM, Brockington IF. Tokophobia: a morbid dread of childbirth Its presence in Great Britain and Grand Cayman, British West Indes. J Psychosom Obstet Gynaecol 2001;22:96 (book of abstracts, suppl 1).

54 Lubin B, Gardiner S, Roth A. Mood and somatic symptoms during pregnancy. Psychosom Med 1975;37:136-46.

55 Fava GA, Grandi S, Michelacci L, et al. Hypochondriacal fears and beliefs in pregnancy. Acta Psychiatr Scand 1990:82:70-2.

56 Sontag LW. The significance of fetal environmental differences. Am J Obstet Gynecol 1941;42:996-1003.

57 Areskog BE. Fear of childbirth in pregnant women. In: di Renzo GC, Hawkins DF, eds. Perinatal medicine. New York: Raven Press, 1986 195-200.

58 Sjogren B. Reasons for anxiety about childbirth in 100 pregnant women J Psychsom Obstet Gynaecol 1997:18:266-72.

59 Areskog B, Kiessler B, Uddenberg N. Identification of women with significant fear of childbirth during late pregnancy. Gynecol Obstet Invest 1982;13:98-107.

60 Szeverenyi P, Poka R, Hetey $M$, et al. Contents of childbirth-related fear among couples wishing the partner's presence at delivery. J Psychosom Obstet Gynaecol 1998;19:38-43.

61 Dick-Read G. Childbirth without fear. New York: Harper and Brothers, 1944

62 Vellay P, Vellay Y. Témoignages sur l'accouchement sans doulerpar la méthode psychoprophylactique. Paris: Le Seule, 1956.

63 Jenkins MW, Pritchard MH. Hypnosis: practical applications and theoretical considerations in normal labour. Br J Obstet Gynecol 1993;100:221-6.

64 Di Renzo GC, Polito PM, Volpe A, et al. A multicentric study on fear of childbirth in pregnant women at term. J Psychosom Obstet Gynaecol 1984:3:155-63.

65 Ryding EL. Investigation of 33 women who demanded a caesarean section for personal reasons. Acta Obstetrica Gynecol Scand 1993;72:280-5. 
66 Siogren B. Fear of childbirth and psychosomatic support-a follow up of 72 women. Acta Obstetrica Gynecol Scand 1998:77:819-25.

67 Royal College of Obstetrics and Gynaecology. The national sentinel caesarean section audit report. London: RCOG Press, October 2001.

68 Bydlowski M, Raoul-Duval A. Un avater psychique méconnu de la puerpéralité: la névrose traumatique post-obstétricale. Perspectives Psychiatriques 1978;4:321-8.

69 Savage GH. Observations of the insanity of pregnancy and childbirth. Guy's Hospital Reports 1875;20:83-117.

70 Beech AB, Robinson J. Nightmares following childbirth. Br J Psychiatry $1985 ; 147: 586$

71 Ballard C, Stanley A, Brockington IF. Post-traumatic stress disorder (PTSD) after childbirth. Br J Psychiatry 1995;166:525-8.

72 Goldberg-Wood S. Post-traumatic stress disorder may follow childbirth. BMV 1996:313:774.

73 Wijma K, Soderquist J, Wijma B. Post traumatic stress disorder after childbirth: a cross sectional study. Journal of Anxiety Disorders 1997;11:587-97

74 Ryding EL, Wijma B, Wijma K. Post traumatic stress disorder after emergency cesarean section. Acta Obstet Gynecol Scand 1997:76:856-61.

75 Allott H. A post delivery stress clinic. Changing Childbirth Update 1998;11:14.

76 Areskog B, Uddenberg N, Kjessler B. Experience of delivery in women with and without antenatal fear of childbirth. Gynecol Obstet Invest $1983 ; 16: 1-12$

77 Ryding EL, Wijma K, Wijma B. Experiences of emergency cesarean section: a phenomenological study of 53 women. BIRTH 1998:25:246-51

78 Ryding EL, Wijma K, Wijma B. Psychological impact of emergency caesarean section in comparison with elective caesarean section, instrumental and normal vaginal delivery 1998. J Psychosom Obstet Gynaecol 1998;19:135-44.

79 Green J, Coupland V, Kitzinger J. Expectations, experiences and psychological outcomes of childbirth: a prospective study of 825 women. BIRTH 1990:17:15.

80 Wijma K, Wijma B. Changes in anxiety during pregnancy and after delivery. In: Wijma K, von Schoultz B, eds. Reproductive life. Advances in research in psychosomatic obstetrics and gynaecology. Parthenon Publishing Group, 1992: 81-8.

81 Hofberg K. Tokophobia a profound dread and avoidance of childbirth. A review. Yearbook of obsterics and gynaecoloy. London: Royal College of Obsterics and Gynaecoloy Press, 2002: 165-74.

82 Benoit D, Parker KCH. Stability and transmission across three generations. Child Dev 1994;65:1444-57.

83 Uddenberg N. Reproductive adaptation in mother and daughter. A study of personality development and adaptation to motherhood. Acto Psychiatr Scand 1974(suppl 254).

84 Simkin P. Just another day in a woman's life? Part ii: nature and consistency of women's long term memories of the first birth experience. BIRTH 1992;2:64.

85 Rachman S. The conditioning theory of fear acquisition: a critical examination. Behav Res Ther 1977:15:375-87.

86 Zar M. Diagnostic aspects of fear of childbirth. Linköping Studies in Education and Psychology Dissertation No 78, 2001

87 Lazarus RS. Emotion and adaptation. New York: Oxford University Press, 1991.

88 Baker AW, Duncan SP. Sexual abuse in childhood: a study of prevalence in Great Britain. Child Abuse Negl 1985:9:457-67.

89 Oppenheimer R, Howells KJ, Palmer RL, et al. Adverse sexual experiences in childhood and clinical eating disorders: a preliminary description. J Psychiatr Res 1985;19:357-61.

90 Bryer JB, Nelson BA, Miller JB, et al. Childhood sexual and physical abuse as factors in adult psychiatric illness. Am J Psychiatry 1985:144:1426-30.

91 Lindberg FH, Distad FJ. Post-traumatic stress disorders in women who have experienced childhood incest. Child Abuse Negl 1985;9:329-34.

\section{ANSWERS}

l. (A) T, (B) T, (C) T, (D) T; 2. (A) T, (B) T, (C) F, (D) F; 3. (A) T,

(B) F, (C) T, (D) F; 4. (A) T, (B) T, (C) F, (D) F; 5. (A) F, (B) T,

(C) F, (D) T; 6. (A) T, (B) F, (C) T, (D) T.

You can access the FULL TEXT of articles cited in Postgraduate Medical Journal online if the citation is to one of the more than 200 journals hosted by HighWire (http://highwire.stanford.edu) without a subscription to that journal. There are also direct links from references to the Medline abstract for other titles. 